\title{
A Review of Measurement Methods of Dissolved Oxygen in Water
}

\author{
Haijiang Tai ${ }^{1}$, Yuting Yang ${ }^{1, *}$, Shuangyin $\mathrm{Liu}^{1,2}$, and Daoliang $\mathrm{Li}^{1{ }^{1, * *}}$ \\ ${ }^{1}$ College of Information and Electrical Engineering, China Agricultural University, \\ Beijing 100083, P.R. China \\ ${ }^{2}$ College of Information, Guangdong Ocean University, \\ Zhanjiang Guangdong 524025, P.R. China
}

\begin{abstract}
Some kinds of checking methods and principle of dissolved oxygen in water were summarized. Such as: iodometric method, current determination method (Clark dissolved oxygen electrode), conductance measurement and fluorescence quenching. The advantages and disadvantages of each method were compared, and fluorescence quenching was discussed. The method uses Ruthenium complex as fluorescence sensitive reagent, which emits fluorescence under the excited light. The quenching accords with Stem-Volmer formula, and the density of oxygen could be deduced by checking fluorescence spectrum.
\end{abstract}

Keywords: Dissolved oxygen, Fluorescence quenching, Environmental monitoring.

\section{Introduction}

With the rapid development of industry and agriculture, a large number of industrial waste water and agricultural drain is discharged to rivers and lakes. At the same time, about $80 \%$ of sewage of city life is discharged directly without handled, towns and rural sewage is discharged in disorder state. As a result, water quality of many locals deteriorating, water pollution and the shortage of water resources increasing seriously. The need of real-time monitoring and effective treatment of wastewater is urgent, and dissolved oxygen content in water quality monitoring is an important indicator.

Dissolved Oxygen (DO) refers to oxygen dissolve in water molecules state, DO is vital for all higher aquatic life (B.A. Cox, 2003; M.A. Best, 2007). A source of DO is atmospheric oxygen infiltrate water body when dissolved oxygen in water is not saturated; another source is released by water plant through photosynthesis. DO is changes as temperature, pressure, salinity changes, generally speaking, the higher of temperature and dissolved salts, the lower of DO content in water; the higher of air pressure, the higher of DO content in water.

\footnotetext{
*Yuting Yang, contributed equality with Haijiang Tai, and they are co-first author.

${ }^{* *}$ Corresponding author.
} 
DO is consumed by reducibility material, such as sulfide, nitrite and ferrous material. Besides, breathing of microbes in the water and oxidative decomposition of aerobic microbes to organic matter can also consume DO. Consequently, DO is the capital of water, and the indication of water self-purification. DO is approximate to saturated value $(9 \mathrm{ppm})$ in natural water, DO content reduce when algae breeding exuberant.

DO content reduce as a result of water polluted by organic matter and reducing material. As to aquaculture, DO content is vital for all aquatic life, such as fish. When DO concentrations are under $4 \mathrm{mg} / \mathrm{L}$, fish will be dying by suffocation. As to human, DO content could not be less than $6 \mathrm{mg} / \mathrm{L}$. When the rate of Oxygen dissolves into water is lower than DO consumption rate, DO content will be reduce to $0 \mathrm{mg} / \mathrm{L}$, anaerobic bacteria breed and water quality will be worse, so DO content can reflect the contaminated level of water, DO content is an important index of contaminated level of water and also a overall indicator of measuring water quality. Therefore, measurement of DO content has important significance to environmental monitoring, and the development of aquaculture industry.

\section{Methods and Principle of DO Measurement}

\subsection{Iodometric Method (GB7489-87)}

Iodometric method (equivalent to international standard ISO 5813-1983) is the benchmark of DO measurement method, it is the first method of DO measurement by using chemical test method, and measurement accuracy is high (Irja Helm, 2009). Its principle is added manganese sulfate and alkaline potassium iodide in water samples, and produces manganic hydroxide. The nature of manganic hydroxide is unstable extremely at the time; it combined with DO quickly, and produces manganese manganic acid:

$$
\begin{gathered}
4 \mathrm{MnSO}_{4}+8 \mathrm{NaOH}=4 \mathrm{MN}(\mathrm{OH})_{2} \downarrow+4 \mathrm{Na}_{2} \mathrm{SO}_{4} \\
2 \mathrm{Mn}(\mathrm{OH})_{2}+\mathrm{O}_{2}=2 \mathrm{H}_{2} \mathrm{MnO}_{3} \\
2 \mathrm{H}_{2} \mathrm{MnO}_{3}+2 \mathrm{Mn}(\mathrm{OH})_{3}=2 \mathrm{MnMnO}_{3} \downarrow+4 \mathrm{H}_{2} \mathrm{O}
\end{gathered}
$$

Add in concentrated sulfuric acid and has combined dissolved oxygen (existence in the form of $\mathrm{MnMnO} 3$ ) react with potassium iodide added in solution, and separate iodine.

$$
\begin{gathered}
4 \mathrm{KI}+2 \mathrm{H}_{2} \mathrm{SO}_{4}=4 \mathrm{HI}+2 \mathrm{~K}_{2} \mathrm{SO}_{4} \\
2 \mathrm{MnMnO}_{3} \downarrow+4 \mathrm{H}_{2} \mathrm{SO}_{4}+\mathrm{HI}=4 \mathrm{MnSO}_{4}+2 \mathrm{I}_{2}+6 \mathrm{H}_{2} \mathrm{O}
\end{gathered}
$$


Take starch as indicator, and titrate iodine released with sodium thiosulfate, to calculate the DO content, chemical formulas as following:

$$
2 \mathrm{Na}_{2} \mathrm{~S}_{2} \mathrm{O}_{3}+\mathrm{I}_{2}=\mathrm{Na}_{2} \mathrm{~S}_{4} \mathrm{O}_{6}+4 \mathrm{NaI}
$$

Where $\mathrm{V}$, is the amount used of $\mathrm{Na}_{2} \mathrm{~S}_{2} \mathrm{O}_{3}$ solution, $\mathrm{M}$ is the concentration of $\mathrm{Na}_{2} \mathrm{~S}_{2} \mathrm{O}_{3}, a$ is the volume of water samples used in titrating. DO could be calculated as following:

$$
D O(m o l / L)=\frac{V \cdot M}{a}
$$

Iodometric method is applicable to clean water, such as source water and surface water. Iodometric method is a kind of traditional measurement method of DO, it has high measurement accuracy, and the measurement uncertainty is $0.19 \mathrm{mg} / \mathrm{L}$. But the method is a kind of pure chemical testing method, time consuming and program trivial, cannot satisfy the online measurement requirements. At the same time, the organic matter easy oxidizing, such as tannic acid, humic acid and xylogen, can lead to disturbance with measurement results.

\subsection{Current Determination Method (Clark OXYSENS)}

Current determination method measure DO content in water according to diffusion rate of molecular oxygen spread through the film This kind of film can only through gas and generally use the polytetrafluoroethylene film. Oxygen through the gas diffusion to electrolyte, reduction reactions occur immediately in the cathode (positive), oxidation Reaction occur immediately in the anode (negative), the current produced is proportional to oxygen concentration, by means of measuring the size of the current can get dissolved oxygen (DO) concentrations.

Oxygen is consumed at the cathode according to the reaction (Yongxia Zhang, 2003):

$$
\mathrm{O}_{2}+2 \mathrm{H}_{2} \mathrm{O}+4 e^{-} \rightarrow 4 \mathrm{OH}^{-}
$$

In response to the production of hydroxyl ions $\left(\mathrm{OH}^{-}\right)$at the cathode, and to preserve the charge balance of the electrolyte (saturated $\mathrm{KCl}$ ) solution, chloride ions react with silver at the anode according to the reaction:

$$
\mathrm{Ag}+\mathrm{Cl}^{-} \rightarrow \mathrm{AgCl}+e^{-}
$$

Therefore, the chloride ions in the electrolyte solution function as a carrier of the electric charges.

Galvanic electrodes use silver or platinum as the cathode and lead, iron, or zinc as the anode: 


$$
\begin{aligned}
& \text { cathode } \mathrm{O}_{2}+2 \mathrm{H}_{2} \mathrm{O}+4 e^{-} \rightarrow 4 \mathrm{OH}^{-} \\
& \text {anode: } 2 \mathrm{~Pb}+4 \mathrm{OH}^{-} \rightarrow 2 \mathrm{PbO}+2 \mathrm{H}_{2} \mathrm{O}+4 e^{-}
\end{aligned}
$$

The measurement speed of current determination method is fast than iodometric method, easy operation and less disturbance, and can realize automatic and continuous detection. However, its oxygenater membrane and electrode easy ageing, when water samples containing the algae, sulfide, carbonate, oil and other material, oxygenater membrane will be jam or damage, need to pay attention to protect and change in time. Besides, it determines the concentration of oxygen relies on the electrode occur oxidation reduction reactions under the action of oxygen. Currently, instruments obtainable in the market belong to the type of Clark electrode mostly, activated at set intervals and oxygenater membrane should be changed regularly. Representative products is a series of portable dissolved oxygen meter of YSI company of United States, this device used widely in our country, such as YSI58 Dissolved oxygen meter, it could complete the test work of laboratory and field effectively, easy to carry and operate, measurement range is $0-20 \mathrm{mg} / \mathrm{L}$, accuracy is $\pm 0.03 \mathrm{mg} / \mathrm{L}$.

\subsection{Fluorescence Quenching}

Fluorescence quenching refers to any process which decreases the fluorescence intensity of a molecule. A variety of processes can cause fluorescence quenching, such as excited state reactions, energy transfer, complex formation and molecular collision (Lakowicz, 1999). This phenomenon may pose challenges for the implementation of fluorescence spectroscopy for water quality monitoring method due to the complex and variable water matrices that exists within water recycling systems and distribution networks. The potential influence on fluorescence measurements from temperature variations, $\mathrm{pH}$, metal ions and oxidation processes need to be considered (R.K. Henderson, 2009).

From the beginning of the 80 s, people have begun to explore the work of applied to oxygen probe of fluorescent indicator. Four alkyl amino ethylene has been adopted for chemical fluorescer, it fall into disuse for its attenuate gradually in 12 hours in application of response with oxygen. Pyrene, Pyrene butyrate and Fluorine anthraquinone are good indicator of oxygen.

Wolfbeis had reported a fluorescent sensor response to oxygen fast in 1984, took pyrene butyrate fixed in porous glass as indicator. The advantage of the sensor is response fast (low in $50 \mathrm{~ms}$ ), and have a good stability. Philip had fixed three fluorescence indicators of coumarin 1, coumarin 103 and coumarin 153 in XAD-4, XAD-8 and silica gel respectively, make comparisons in sensitivity, launch of strength and stability, coumarin 103 fixed in XAD-4 is the best option as interface in fiber optic oxygen sensor. Fiber optic oxygen sensor takes it as indicator has the application scope widely. Later, organic compounds of transition metal ( $\mathrm{Ru}, \mathrm{Os}, \mathrm{Re}, \mathrm{Rh}$ and $\mathrm{Ir}$ ) got attention for its special performance. In generally, selecting ruthenium complex as 
indicator. Fluorescence intensity of ruthenium complexes exist one-to-one correspondence with the partial pressure of oxygen. Excited state of ruthenium complexes has long life, no need oxygen; its chemical composition is very stable, and insoluble in water. During the process of metal ligand charge transfer (MLCT) from ground state to excited state of Ruthenium complexes of chromium, the nature of excited state is closely related with the ligand structure, usually with the ligand conjugated system increases, the fluorescence intensity and fluorescence life expectancy increases.

The most common method of optically detecting oxygen has been through the measurement of the fluorescent intensity of suitable fluorophores, the intensity decreasing with increasing oxygen concentration (Lee, S., Shin, 2001; Choi, M.M.F., 1999).

The oxygen quenching process is described by the Stern-Volmer equations:

$$
\begin{gathered}
\frac{I_{0}}{I}=1+K_{S V} p O_{2} \\
\frac{\tau_{0}}{\tau}=1+K_{S V} p O_{2} \\
K_{S V}=k \tau_{0}
\end{gathered}
$$

Where $I$ and $\tau$ are, respectively, the fluorescence intensity and excited state lifetime of the fluorophores, the subscript 0 denotes the absence of oxygen, $K_{S V}$ is the Stern-Volmer constant, $k$ is the diffusion-dependent bimolecular quenching constant, and $\mathrm{pO}_{2}$ is the oxygen partial pressure. According to the actual measurement of fluorescence intensity, $I_{0}, I$ and $K_{S V}$, DO concentration can be calculated.

Much has been published on optical oxygen sensors that measure the intensity of phosphorescence. It has now been established that these sensors have many drawbacks. These include susceptibility to light source, detector drift, and changes in the optical path (A.K. McEvoy, 1996). These effects can be minimized by operating the sensor in the time domain instead of in the intensity domain. The lifetime $\tau$ is an intrinsic property of the lumophore that, unlike intensity, is virtually independent of external perturbations. The fluorescence is quenched in the presence of oxygen, and this quenching is described in Eq. (13). Using this relationship, the dissolved oxygen concentration can be measured.

Phase modulation fluorometry is the preferred method of conducting fluorescence lifetime measurements particularly with long lifetime fluorophores due to the simplicity and low cost of the equipment required in comparison to direct lifetime measurements. With a sinusoid ally modulated excitation signal, any fluorescence produced will also be modulated at the same frequency but will be time delayed, or phase shifted, relative to the excitation signal. The relationship between the lifetime, 
$\tau$, and the phase angle, $\theta$, for a single exponential decay is given by (A. Campbell, 2004):

$$
\tan \theta=2 \pi f \tau
$$

Where, $f$ is the modulation frequency. The optimum modulation frequency that maximizes sensitivity is generally found by adjusting the frequency so that the phase change between extremes of measurements ( 0 and $100 \%$ DO) is maximized.

Fig.1 illustrates the principles of phase modulation fluorometry. Many optical oxygen sensors have been tested that utilize phase modulation or other lifetime measurements for oxygen and DO measurements.

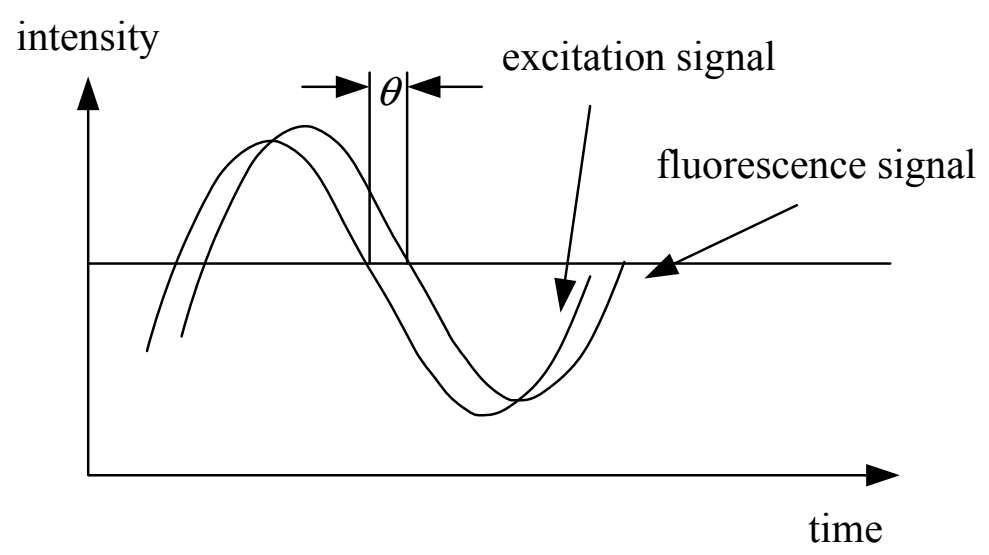

Fig. 1. Illustration of phase shift in fluorescence emission

Experiments show the method overcome the disadvantage of iodometric method and current determination method, photochemical stability and reproducibility is very good, without delay, high precision, long life, Can be real-time monitoring of dissolved oxygen in water, The range is generally $0 \sim 20 \mathrm{mg} / \mathrm{L}$, the general accuracy is lower to $1 \%$, response time is lower to $60 \mathrm{~s}$.

\subsection{Other Detection Methods}

Conductometry: Use conductive metal thallium or other compounds to react with dissolved oxygen to produce the thallium ion. Through the determination of water conductivity delta, can get the concentration of dissolved oxygen (DO).Experiments show that increase by $0.035 \mathrm{~S} / \mathrm{cm}$ of conductivity is equivalent to $1 \mathrm{mg} / \mathrm{L}$ dissolved oxygen (DO). This method is the most sensitive method for monitoring dissolved oxygen (DO). 
Anodic stripping voltammetry: Using conductive metal thallium to react with dissolved oxygen to produce the thallous ion. Then use template leaching to determine the concentration of the Tl+ ions, thereby obtained the concentration of dissolved oxygen (DO). This method has the advantages of sampling quantity is little, high sensitivity and temperature effect is not seriously.

\section{The Present Situation of the Research on DO in Water at Home and Abroad}

Conventional program of water quality tests in China is analysis sampling in laboratory, the middle part of the work complexity, leading to long time detection, unable to get the water quality timely. Now some of the domestic unit and research institutions have developed some minitype dissolved oxygen detector, general base on current determination method, such as JPSJ-605 dissolved oxygen analyzer of Shanghai ray magnetic instrument factory, H-BD5W handheld water quality instrument of Beijing BeiDouXing industrial chemical institute, there is still a gap in measurement speed with foreign similar instrument. Domestic fluorescent DO sensor also has some research (Xingliang Wang, 2009; Zhaoquan Lu, 2007), technology has reached the international average, but less research on commercialization. Foreign research general use of new dissolved oxygen meter based on fluorescence quenching effect (Xiaoli Xiong, 2006; Bharathibai J. Basu, 2005; R.N. Gillanders, 2004), representative products are the MICROXI dissolved oxygen meter of DMP company of Switzerland, OXYMON oxygen measurement system of United States, measurement precision is high and speed is fast, and can be used in remote measurements.

In general, most of the commercial dissolved oxygen meter on the market is based on Clark oxygen electrode, fiber-optic oxygen sensor based on fluorescence quenching method is less.

\section{Conclusion}

Currently the mainstream of international development is fiber-optic oxygen sensor based on fluorescence quenching, According to fluorescence quenches characteristics, use the following method to realize dissolved oxygen detector: optical signal emitted by the source filter to a area of the fluorescent indicator, dissolved oxygen react with fluorescent indicator, causing change of the light intensity, wavelength, frequency, phase, polarization and other optical characteristics, then arrive in the detectors and signal processing devices, get information of the concentration of dissolved oxygen.

To prevent contamination, corrosion and interference of water biological, anti-interference ability is the key of instrument. We should be research on chemical stability of sensing membrane, anti-corrosion apparatus and stability of the circuit.

View of the optical sensor based on fluorescence quenching method with high accuracy and strong anti-interference ability, and good repeatability and stability, can be used for water quality measurements in aquaculture and water pollution level measurement in agriculture, so research on this sensor has important practical applications and commercial value. 
Acknowledgements. This work was supported by the programs "Development and Applications of sensor network applied to monitor bloom of blue-green algae in Taihu Lake" (2010ZX03006-006), and Beijing Natural Science Foundation "Integrations methods of digitalization technologies in intensive fish farming" (4092024).

\section{References}

1. Cox, B.A.: A review of dissolved oxygen modeling techniques for lowland rivers. The Science of the Total Environment (314-316), 303-334 (2003)

2. Best, M.A., Wither, A.W., Coates, S.: Dissolved oxygen as a physico-chemical supporting element in the Water Framework Directive. Marine Pollution Bulletin 55, 53-64 (2007)

3. Helm, I., Jalukse, L., Vilbaste, M., Leito, I.: Micro-Winkler titration method for dissolved oxygen concentration measurement. Analytica Chimica Acta 648, 167-173 (2009)

4. Zhang, Y., Johnson, D.: Supersaturated dissolved oxygen measured by the phosphorescence decay rate. Sensors and Actuators B 96, 379-384 (2003)

5. Lakowicz, J.R.: Principles of Fluorescence Spectroscopy. Academic/Plenum Publishers, New York (1999)

6. Henderson, R.K., Baker, A., Murphy, K.R., Hambly, A., Stuetz, R.M., Khan, S.J.: Fluorescence as a potential monitoring tool for recycled water systems: A review. Water Research 43, 863-881 (2009)

7. Lee, S., Shin, Y.B., Pyo, H., Park, S.H.: Highly sensitive oxygen sensing material: thin silica xerogel doped with tris(4, 7-diphenyl-1, 10- phenanthroline)ruthenium. Chem. Lett. 4, 310-311 (2001)

8. Choi, M.M.F., Xiao, D.: Linear calibration function of luminescence quenching-based optical sensor for trace oxygen analyses. Analyst. 224, 695-698 (1999)

9. McEvoy, A.K., McDonagh, C., MacCraith, B.D.: Dissolved oxygen sensor based on fluorescence quenching of oxygen: sensitive ruthenium complexes immobilized in sol-gel-derived porous silica coatings. Analyst. 121, 785-788 (1996)

10. Campbell, A., Uttamchandani, D.: Optical dissolved oxygen lifetime sensor based on sol-gel immobilization. IEE Proc.-Sci. Meas. Technol. 151 (2004)

11. Wang, X., Ren, Y., Chen, S.: On-line DO survey meter based on optic fiber sensor. Mechanical \& Electrical Engineering Magazin. 26, 89-91 (2009)

12. Lu, Z., Zhao, X.: Development of the fluorescence quenching seawater dissolved oxygen detector based on AT89S52. Journal of Hefei University of Technology 30, 174-177 (2007) (in Chinese)

13. Xiong, X., Xiao, D., Choi, M.M.F.: Dissolved oxygen sensor based on fluorescence quenching of oxygen-sensitive ruthenium complex immobilized on silica-Ni-P composite coating. Sensors and Actuators B 117, 172-176 (2006)

14. Basu, B.J., Thirumurugan, A., Dinesh, A.R., Anandan, C., Rajam, K.S.: Optical oxygen sensor coating based on the fluorescence quenching of a new pyrene derivative. Sensors and Actuators B 104, 15-22 (2005)

15. Gillanders, R.N., Tedford, M.C., Crilly, P.J., Bailey, R.T.: A composite sol-gel/fluoropolymer matrix for dissolved oxygen optical sensing. Journal of Photochemistry and Photobiology A: Chemistry 163, 193-199 (2004) 